\title{
Pigs and Packers
}

\author{
Angela Calabrese Barton · Jaime Grinberg • \\ Katherine Richardson Bruna
}

Received: 16 October 2006/ Accepted: 16 October 2006/ Published online: 22 December 2006

(C) Springer Science+Business Media B.V. 2006

This study presents us with a number of issues that add complexity to the taken-forgranted practices of teaching immigrant children in the US. Furthermore, by contextualizing the events and dialogs within the larger contexts and contradictory discourses of the purposes of schooling vis-à-vis the globalizing dimension of ethnoscapes, the debate forces us to engage in theorizing within the discourses of correspondence (reproduction), resistance, agency, and hope. In what follows we engage in conversation where we each take turns interrogating, problematizing, and playing the role of the provocateur in order to elicit dialog among us and to advance the tremendous ideas put forth in Pigs and Packers. Across our comments, we ultimately struggle with three big ideas:

- How are youth's and teachers' stories about science, self and future constructed within the discourse of science learning, ELL, dissection, and immigrant status? What roles do teachers, curriculum, institutional structures and local, national, and global priorities play in constructing these stories?

- How do youth and their teachers work to and/or learn to resist disrupt "normative stories" of science, self and future?

- In what ways does place shape the construction of such narratives?

Jaime: A powerful undercurrent across this text is place, and I find myself as a reader taking up my own place both with and against the text. My background is not in science education and my own high school science experiences were not in the US.

\footnotetext{
A. Calabrese Barton ( $\square)$

Michigan State University, East Lansing, USA

e-mail: acb@msu.edu

J. Grinberg

Montclair State University, New Jersey, USA

e-mail: grinbergj@mail.montclair.edu

K. Richardson Bruna

Iowa State University, Ames, USA

e-mail: krbruna@iastate.edu
} 
However, I immediately resonated with pig dissections for a number of reasons. Pig dissection is certainly not exclusive to this particular classroom, school, or community. In many schools it is performed as routine in the first year of science in American high schools regardless of location, resources, and class, ethnicity, and language. For example, in my neighborhood high school, students do pig dissections in Honors science classes and also in Advanced Placement Biology. However, as the authors point out, beyond the clear difference in terms of social class, cultural capital, and classroom resources, the way in which teachers teach and their knowledge of the subject matter can make an extraordinary difference in how students build themselves as "young scientists," in an identity sense, as well as in consequence: How they immerse in the disciplinary discourse which will enable them actually to engage at some point in a critique of whose science, for what purpose, under which conditions, and for the benefit of whom.

Angie: The geopolitical terrain in which the pig dissection takes place is complex, indeed. The families of the students in this narrative depend upon the meat packing industry for economic livelihood. Family identities are tied to the industry, to some extent, and vast social networks both with and against the industry form among immigrant families. However, Linda's students' association-and assumed futures -within the industry focuses attention on social and economic segregation and institutional racism in the US. When Linda's student, Enrique, says he is not going to work for the meat packing industry (after it is assumed in Linda's comment that he will) she backs off, praising him for the idea that he might attend college. It is a discourse, however, that remains below the surface in Linda's class, but one that seems still ever-present. One has to wonder if the promise to conduct a pig dissection is a promise to sustain the narrative about their futures.

As I think about this complex terrain negotiated by Linda and her students, I wonder how these narratives about pigs, meat packing, identity, and futures are rooted in a sense of place. Each of these narratives assumes, to some degree, that students have a "connection" to pigs, a knowledge of and a relationship with the meat packing industry, and that somehow their futures are inextricably linked to both. Attention is given to place in so far as the students are ascribed futures in this place-the place of the meatpacking industry-but are not granted authority over how this space frames their local knowledge of pigs or the relationship between pig dissection and life in a meat packing town. In a recent book, Jason Corburn (2005) argues that scientists and other professionals, which I would argue often include teachers and educational researchers, tend to assume that lay people have little substantive knowledge to offer complex scientific analyses except possibly perceptions and values. If we look closely at the narratives presented in Pigs and Packers we can see that the youth do indeed offer complex perceptions and values related to the meat packing industry, but they offer much more. They have a complex, local knowledge of the relationship between science and society and position within that relationship. I am referring not just to the conversation about whether its wasteful to dissect fetal pigs, although I think this is an excellent example. I refer also to discussions of pregnancy, miscarriage, how butchers learn to cut meat, and whether and if knowledge of pig anatomy matters in any effort to disrupt the normative expectation for their futures. It is not just that these youth understand something about pigs; it is that they understand how participation in the pig activity-a science activity that one might view as an "entry into a "real" science community-actually positions them as outsiders to the worlds of science. These experiences may be 
wasteful because they are meant to introduce the youth to worlds they already know only too well.

Jaime: Place cuts across social, material, historical, and political concerns. To return for a moment to the issue of material resources in the class, such as the lack of adequate equipment, points to the well documented issue of the "savage" inequalities, which is exacerbated in schools with significant numbers of historically marginalized populations. I recently visited a high school in a neighboring urban school where the so-called science labs didn't have a sink and did not have the plumbing for the needed water. Therefore, science classes were done from the book only. Furthermore, in many countries I visited, including Argentina, where I was born and grew up, facilities for the teaching of sciences in numerous schools are not existent and many teachers are not certified.

Katherine: On this point, it's important to state more explicitly, as Jamie is pointing out, that the "savage" inequalities in the education of some immigrant children are best viewed as global in nature. In the case of my research, Captainville has a "shadow" city relationship (I use this term as the "unofficial" opposite of the official "sister" city designation) to a particular rural community in Mexico. The poverty of those schools can be seen in the physical grounds and in the classrooms. There is lack of adequate lighting, air conditioning, textbooks, and other learning supports, as well as of qualified teachers. The teachers in this community (who are not, notably, of this community) are docentes or "providers of educational services"; they have not gone through teacher preparation programs and thus have no background in pedagogy. When students who have attended these skills enroll at Captainville, they bring experiences structured by those "savage" inequalities with them, compounding the replication of the socioeconomic hierarchy that already exists. Their educational histories and their non- or limited English proficient status, coupled with the fact that many, as plant workers in Captainville, are also undocumented, means that these individuals have very limited economic and social mobility. And these processes of economic exclusion become linked to race, (re)producing a tenacious Mexican underclass in Captainville. This produces a particular "structure of feeling" in the community, as Williams would say, that give it its sense of place. The longer-term effects of the coupling of the segmentation of the economy with, as this research attests, the segmentation of educational opportunity in Captainville, and other communities like it, are not yet clear. But we need to be watching. The framing of the pig dissection in the English Learner Science course as preparation for these students' perceived future work at the plant is evidence of this interwoven economic and educational segmentation.

Angie: The very idea of dissection has been so indelibly linked to what it means "to do science" at the middle and high school level in the US that many of the students with whom I work in high poverty communities-and who will not have opportunities to conduct their own dissections because school resources are limited or because the teacher/administration feels students are not responsible enough to handle dissection equipment-speak to the importance of dissection in school science. When asked about "What they want to do in school" many of these students say "dissection." When asked about "what science is," many of these students invoke dissection. That the act of dissection-an act embued with cultural meanings-becomes the epitome of a "desired" science education speaks to its power in the place of school science and identity formation in science education. 
Katherine: And that's why understanding Linda's framing of the dissection in this classroom is so important. If the act of "dissection" connotes, as Angela is suggesting, the apex of a science-learner identity, the fact that Linda explicitly and repeatedly detaches the dissection from the students' science-learning futures tells us something significant about knowledge production and access in that context.

Jaime: The stratification in access to knowledge is savage within and across multiple places. Sometimes I would be satisfied even if the only scientific knowledge students' access is the Western dominant mainstream (and probably colonizing), particularly when alternatives have not been scrutinized at any level. I am also bringing up this point because it seems to be that for many students in this class have no school access in their native places. In a sense, as the mother in the introductory quote to the article remarks, the hope in education as a mean for social mobility is huge. Many immigrants move from the peripheries to the centers of economies not only searching for jobs, but also searching for improving opportunities for their children and public education could fulfill this expectation. What the article is telling us is that these opportunities do not exist as the structure of labor divisions predetermined what spaces exist and what spaces do not exist.

Angie: Jaime you powerfully remind us of the savage inequalities faced by minorities in the US in terms of access to science labs, equipment and high quality instruction. Katherine's story suggests that these inequalities are not just solved by adding labs or science experiences, because the narratives that shape these experiences can be equally as damaging. So, what do we want for our students in our efforts to build a science for all? How should real world, rigorous science experiences be presented? What makes their presentation different based upon place? In other words, what should a pig dissection look like for immigrant youth in a meat packing community? What kinds of narratives should emerge beyond the curricular focus of learning about pig anatomy and its similarity to human anatomy? How should questions of economic futures, the relationship between science and society emerge in productive ways? These are questions raised by this manuscript, and which I believe cut much deeper than the pig dissection and meat packing context.

Jaime: I agree that these narratives shape identity and cultural meaning vis-à-vis ways of knowing, constructions of legitimate knowledge and its ownership and contested discourses. Interestingly, in our own research we found a couple of connected issues: ESL/bilingual classes are not necessarily liberatory spaces or places where alternative narratives and discourses are validated, legitimated, and owned Grinberg and Saavedra (2000). For the contrary, in many instances these places and the pedagogical practices are purposely guided to de-culturalize and a-culturalize students and teachers, by the emphasis on normalizing and domesticating, thus serving as a disciplinary practice, which means:

A set of discourses, norms, and routines that shape the ways in which a field of study constitutes itself; ... connects with historical, political, cultural, and economic contexts but are enacted within specific, local, and contingent institutional arrangements, and ...entails the establishment of conventions, agreements, and rules that regulate and legitimize current ways of distinguishing among 'best practices', desired outcomes, academic rigor, and valid knowledge claims. (Anderson \& Grinberg, 1998, p. 330)

Angie: Your point about how places and pedagogical practices can de-culturalize and a-culturalize students and teachers returns me to one of the questions we began 
with: What narratives unfold in science class, and how are these narratives sustained, constrained, made possible or punctuated by the space of the learning environment and the participants within? There are two points about narrative that I want to keep in mind as I use this lens to make sense of Katherine's work. The first is that narratives are cultural products and expressions of identity. As Connelly and Clandinin remind us, people live their stories in an ongoing experiential text and tell their stories in words as they reflect upon their lives and explain themselves to other (Clandinin \& Connelly, 2000). The second point is that because narratives are recursive they can foster "new forms of power," configuring new ways for individuals and communities to fight against injustices as well as to create new identities.

Narrative takes on several meanings here, in the same way it does in the pig dissection story. We have the narratives that youth share with each other and with teachers as they seek to creating meaningful spaces in the classroom. For example, there are the stories about miscarriage and pregnancy that get taken up as legitimate discourse in the science classroom, and serve as points of entry into the science discourse community. There are also narratives about who "we," "I," "you," and "they" are in science class as notions of science, scientific/academic identities, and futures play out in school talk. As pointed out in the manuscript, Linda separates herself from her students when talking about the position vis-a-vis the meat packing facility. Finally, we also have narratives of science, success, and the purposes of schooling. Indeed, the pig dissection story leaves one wondering what schooling is about. Each of these levels or kinds of narratives is deeply grounded in place.

Katherine: Taking up Angela's invitation to reflect on identities, there is, of course, another narrative implicitly present in the work and that is of my own positionality. I am guided by the goal of being one of Aronowitz and Giroux's (1985) "transformative intellectuals"; I want to actively participate in efforts to create positive social change. Because of this research, I'm trying to do that by being involved in Iowa's professional development initiatives for science teachers of English Learners and changing the culture of science education by working with the State. But I do so mindful of two limitations. One of these is that the State has what Lipsitz (1998) calls a "possessive investment" in the existing power structure so efforts to effect change will necessarily be partial, about re-forming existing structures rather than dismantling and transforming them. (I really place more power in after-school programs like those Angela has been involved with. These, because they exist outside of institutionalized school culture, can be more transformative, particularly in the ways they stand to recognize local knowledges and move out into and involve communities.) The second is that I, as an individual privileged by race, class, and language, can never, as Spivak (1988) points out, truly speak for the Mexican community I research, despite how closely I get to know some of them. Because of this, I have begun to do collaborative work, inviting Mexican students, for example, to present with me at conferences. I am very much aware, as I wrote about in an essay in Anthropology News, that some students would take issue with my depiction of Linda as a benevolent oppressor. They regard her as a lifeline. Who am I to question the esteem they hold for her? Yet, I do question it because it relies on a power-play of desires-hers to assert, albeit dysconsciously, her privilege and theirs to feel like their needs are being met, even if only minimally so, because their expectations for just treatment are so low. This is what saddens me most. They don't expect teachers to care, in Noddings' (1984) ethics-based sense of the word. But in saying this, I am implying they have a kind of false-consciousness and run the risk of 
using my institutional position to further oppress through misrepresentation. This is the quagmire we enter into when we do research on historically subjugated groups, particularly if we are not members of those communities. I tried to include enough discourse data in the Pigs \& Packers piece so that the audience could evaluate and "trust" my interpretation. But I think the issue of who speaks for whom, why, and to what ends, needs to be kept alive. That is important to the credibility and integrity of our work. So I am aware of how there is a narrative of "otherness" in this piece, even though my goal is, ultimately, transformative.

Jaime: Yes, and so another narrative that I think we must raise is how these spaces create a discourse of "otherness." As part of the national Latino/a Education Research Agenda and Policy Project (NLERAP), we conducted a project entitled "Con Pasión y con Coraje: The Schooling of Latino/a Students and their Teachers' Education," in which we looked into how teacher preparation in the US has addressed the education of Latino/a students Grinberg, Goldfarb, and Saavedra (2005). One of our conclusions has been that it has served to construct paradigms of "otherness." We, in contrast, proposed a shifting towards learning from the students' narratives. For this to happen, teachers need not only the intellectual and methodological critical tool, including an analysis of power, and the subject matter knowledge in terms of the multiple and competing disciplinary paradigms, but also a type of libratory disposition that, as also Nieto or Fischman have eloquently articulated, has to incorporate the body, the emotions (Pasión y Coraje). One or the other would be enough if teachers are willing to learn from their Latina/o students and recreate their curricular and pedagogical places, often by transgressions and at times transforming the institutional arrangements that perpetuate and reproduce in a Bourdieuan sense the location and stratification of Latina/o students. Therefore, I would further state that the very same existence of a segregated space for a science class for ELL or ESL students is problematic and could become a place for segregation, marginalization, and alienation of students (and often of teachers too). Thus, the curricular and pedagogic are mingled with the structural and organizational arrangements at the school level, district level, and community level. I think that Katherine addressed that with enough clarity. Actually, I would have been surprised if the students' narratives, voices, discourses, were legitimized given the context and given the teacher's ways of knowing.

The contribution of this work in this point is that the students' voices come through and that opportunities abound to convert this very same segregated space into a transformative experience had the teacher known what to do and how to do it, in spite of the poor material resources. It is also then, that the ideological constructs of the teacher, the school, and the system, serve to contain, constrain, and disregard these students' narratives. Yet, as I also need to think more about Augusto; resistance is taking place in numerous ways because students did not seem to abandon who they are and what they knew, including potential misconceptions. Ultimately, this paper invites us also to focus on the power of pedagogy. I want to echo Angie's remark on place and add that place in this ecological sense is not necessarily oppressive or liberatory by definition. It is the type of practices and meanings that shape how in a dynamic sense place gets reconstructed.

Angie: Yet little or no attention is given in national debate around such transformative spaces. So much energy is devoted to a knowledge base for teaching that focuses on knowledge, skills and dispositions that new teachers should have upon certification. Yet, little of this talk actually takes up how much of this "knowledge" is really about a practice of seeking to create transformative spaces. How ought 
teachers be thinking about the figured worlds of schooling and their own "place" in that world? How might this shift how teachers learn to ask hard questions about the knowledge, skills and dispositions of teaching and how they might be used to transform the current figured worlds of schooling?

Like you, Jaime, we have also been focusing on what youth do to create these transformative spaces for themselves and others. My research group and I have come to be particularly interested in the narratives that girls use to gain access to school science both inside and outside the classroom (i.e., the stories they share with one another) and how this is linked to place. We are also interested in how the embrace of these stories by "others" in the classroom can shift the classroom/ institutional narrative about who can do science and what it looks like to be scientifically literate. We have noted that the girls with whom we work craft narratives that explicitly draw on their cultural capital and non-traditional funds of knowledge in order to create a school science discursive culture that is more congruent with minority students' personal experiences and life-worlds. Such non-traditional funds of knowledge include family and community knowledge, students' personal experiences in popular culture, material resources as well as social relationships. Yet, we have also noted that the girls utilized story telling as a school science practice to actively create participative spaces for themselves in the science classroom, to bolster their science authority and social positioning in the classroom. This search for legitimacy in the classroom through narratives opens up new ways of understanding the playful, yet problematic, relationship between Linda and her students.

Jaime: I am reminded of new sociology of education of the 1970's. The new sociology placed little hope in human agency at the school level, as change would only be conceived within a larger social structural change. In sharp challenge of social reconstructionism and some other progressive perspectives that had the hope that schools in general, and teaching in particular, would reshape the social order, the new sociology argued that school and teaching would radically change only if socioeconomic structures change first. Yet, the authors of this article also place room for hope by fostering an ethics of caring. Thus, I would ask the question if an ethics of caring would alter structural inequities, how this could happen in the context of the community where the school is inserted?

Katherine: Jaime is pointing out a conflict between what is at once the hopeful yet deterministic tone of the piece. Avery Gordon (1997) begins her breathtaking book "Ghostly Matters: Haunting and the Sociological Imagination" with this Patricia Williams' quote: "That life is complicated is a fact of great analytic importance." In the structure-agency debate that Jaime references, I'm not sure there are uncomplicated answers; that is, I'm comfortable saying, on the one hand, that class is overdetermining in a capitalist society while also saying, on the other, that classrooms can be spaces for hope. I'm reminded here of Freire's (1988) discussion of limit-situations, the situations we encounter that impose limitations on our freedom. Freire talks about these in a hopeful sense: "[I]t is not the limit-situations in and of themselves which create a climate of hopelessness, but rather how they are perceived by men [sic] at a given historical moment ... As critical perception is embodied in action, a climate of hope and confidence develops which leads men [sic] to attempt to overcome the limit-situations" (p. 89). Thus, by coming to critical consciousness of the limit-situations, people can alter their perception and their actions to create change. Science classrooms are places where we can begin to effect material change and this requires seeing how things could be "otherwise" (Greene, 2001, p. 70), not 
naturalizing the segmented economic system in Captainville as an inevitable part of the social order but a constructed system that serves particular interests at the expense of others. In an earlier exchange with Jaime, he invoked Fanon (1963), who says that only violence can destroy the marks of violence. If Mexican students at Captainville are subjected to the kind of symbolic violence we see represented in this science classroom, then a kind of "revolutionary" science instruction, oriented towards humanization and transformation, one that asks them, as Angela suggests earlier, deconstructing what science-learning means for them in this community, is what's needed. This is Angela's idea of science for social justice Calabrese Barton (2003) that has entranced me as I've begun to work more and more closely with this population. And it's a dangerous idea in that it makes people uncomfortable. But that's precisely how we know it's an important one.

Jaime: The problem, I argue, is not teacher power but how the teacher uses her power. It is not about abdicating the responsibility as an adult and as a professional to "share" power, but utilizing power to create liberating spaces, for engaging in meaningful learning, and in providing opportunities for alternatives and choices. I agree with the authors that "preparing" them for their future jobs is reproductive Bourdieu and Passeron (1977) in spite of Linda's intentions to motivate the students. Certainly class is an issue as the authors clearly presented. It is interesting to see how this plays also among the students in their interactions with each other. An alternative explanation to Augusto's actions can take us into a different discourse. For instance, we can speculate that there might have been gender issues in Augusto's or Linda's posturing in front of the class. For Augusto might have been attempting to position himself not only in relation to Linda, but vis-à-vis his fellow students. His search for legitimacy given his personal experience also would position him in an asymmetric powerful arrangement with his classmates. Furthermore, I would speculate that perhaps it would reproduce Augusto in the role of the colonized minority that, as Fanon (1963), Memmi (1965), and also Freire (1970) suggested, could utilize his "mediating" position to his advantage by reproducing dependency. This pattern of behavior is common among rural communities in Mexico, where a local "caudillo" becomes such because of his brokering skills, the legitimization of his role by colonizing agents, and the delivery or taking away of some goods to the clients, which Eisenstadt and Roniger (1984), Roniger (1990) documented in their analysis of patron-client relations in Mexico and Brazil.

Katherine: I am intrigued by Jaime's interpretation of Augusto's “domination” of others in the classroom and, in fact, will be looking at the nature of effect of his power more closely in an upcoming manuscript. But I (enter my positionality) like to read Augusto's interactions with Linda as limit-acts directed, as Freire (1988) says, at "negating and overcoming, rather than passively accepting, the 'given", [that all Mexican students want to work in the meatpacking plant, have no previous "scientific" knowledge, etc.] (p. 89). The hope I talk about earlier is in this vein. I see, in his acts, power, and, in that power, the potential for transformative science teaching. But the teacher has to follow through, wielding her power differently in the classroom.

Angie: Your point about how a teacher uses her power calls attention to what exactly we might mean by power, and the import that has for making sense of Pigs and Packers. Embedded in your points, Jaime, is a Foucaultian construction of power, where "power is neither given, nor exchanged, nor recovered, but rather exercised, and ... only exists in action" (Foucault, 1980, p. 89). What I find useful 
here is that, among other things, this view underscores how all people involved in a power relationship are the vehicles of power, not the point of application. Pigs and Packers reminds me of how Kozoll and Osborne (2004) talk about the power of migrant workers to act within power relations to elude control by the system, or at least aspects of that system, as we see Augusto doing in his interactions with Linda. The dance they engage in together in the classroom is about control and the writing of identities. Indeed the public discourse around science education, little attention is paid to how cognitive goals (in both form and expression) may be deeply routed in sociocultural traditions. Youth are engaged in power relationships that cut across many social, cultural, economic, and academic boundaries. Brickhouse and Potter (2001) have argued youth chose to engage in particular kinds of science based on how they see themselves as individuals. It is important, as pointed out earlier, to understand how identity formation happens within power relationships and that youth activity construct identity along with the ways they chose to do science in response to those power relationships as well. In Pigs and Packers we can see how the youth actively construct themselves as packers both through and against the science they are to learn. Science, a way of knowing, a culture, a privileged discourse in western society, gets turned around, and is used to foster the construction of an identity outside of science.

Katherine: The question I think we also need to raise is how students respond to transformative approaches to science education when/if they see themselves mis/ represented back at themselves as "oppressed" by European science? From my work with these students, I know that this is an uncomfortable representation. Through some co-teaching experiences where I have tried some transformative approaches, I know they can easily fall flat. Personally, I feel my identity as a race, class, and language-privileged individual worked against what I was hoping to do. An important part of the equation would be, then, the ability of the teacher to garner the trust of the students and this could be facilitated, not ensured, by a shared cultural identity. This points to some important infrastructure transformations that need to happen for the transformative agenda in science education to take hold-the preparation of science teachers from underrepresented communities, for one thing (which is hindered by the lack of more culturally responsive teaching-a desperate cycle, indeed). But, as Jaime reiterates, there are places in Linda's pig dissection lesson, where she could have taken a more inquiry-based stance, one that, at the very least, recognized the personal connection her students had to the activity. A "revolutionary" teaching identity is not necessary for this to happen. Linda simply missed a rich opportunity to explore her students' connection and, as it turns out, their very science-authentic ethical concerns.

Jaime: It is obvious to me through the rich accounts of the dialogs in the class, that Linda's problem is also her ignorance of science-as a body of knowledge, a discourse community, a place of privilege. There are so many missed opportunities to build a more intellectually engaging experience, that it cannot be intentional. Furthermore, not enabling students' experiences to be part of the dialog also misses the opportunity to challenge potential misconceptions and gaps in the students' knowledge. For instance, the fact that two students had experience taking off skins ("pelando") of animals and that this was ignored, missed the chance not only of modeling, or if nothing else of legitimizing the students, but also the opportunity to examine possible alternative ways of engaging in the procedures or engaging on why the skin is taken out, what do you do with the skin, how the skins are different, etc. 
Or, the issue of the preserving liquids is also a manifestation of missed opportunities. But, it could be a combination of numerous factors. Perhaps time and scope could be a reason to make the instructional decision to not focus on these questions. However, it seems to be that ignorance of the subject matter and a lack of an inquiry disposition are also explanations for this "null" curriculum.

Katherine: And that's just it, Jaime. Traditional curricular issues of time and scope are going to need to be rethought given the context of globalization and the demographic changes it brings. Opportunities to observe the demographic, social, cultural, linguistic, economic, political, historical transitions taking place in communities like Captainville need to be seized because we can learn so much about how new cultural forms evolve out of contact, conflict, and convergence. We stand to learn so much more about the concept of "culture" itself which I think we'd all agree is overused and under-understood. For science education, the point here is that the cultural, linguistic, economic, political, historical difference brought by globalization does not merely layer on to a fixed and rigid community; it becomes a fundamental part of that community in ways that need to be explored. In this way, science education in this age of globalizing communities cannot be understood as taking approaches to instruction oriented toward homogeneity in population and perspective and sprinkling on top of those some effective "multicultural" or "EL" strategies. Science education, whether we admit it or not, is being transformed by the very presence of difference in science classrooms. We could ignore the organic changes and shop around for professional development workshops that "train" teachers in "universal access" strategies, or we could attend to the organic changes and learn from what the students themselves show us about what they want and need.

\section{References}

Anderson, G., \& Grinberg, J. (1998). Educational administration as a disciplinary practice: Appropriating Foucault's view of power, discourse, and method. Educational Administration Quarterly, 34, 329-353.

Aronowitz, S., \& Giroux H. A. (1985). Education under siege: The conservative, liberal and radical debate over schooling. South Hadley, MA: Bergin \& Garvey.

Bourdieu, P., \& Passeron, J. (1977). Reproduction in education, society, and culture. London: Sage.

Brickhouse, N., \& Potter, J. (2001). Young women's scientific identity formation in an urban context. Journal of Research in Science Teaching, 38, 965-980.

Calabrese Barton, A. (2003). Teaching science for social justice. New York: Teachers College Press.

Clandinin, D. J., \& Connelly, F. M. (2000). Narrative inquiry: Experience and story in qualitative research. San Francisco: Jossey-Bass.

Corburn, J. (2005). Street science. Cambridge, MA: MIT Press.

Eisenstadt, S., \& Roniger, L. (Eds.) (1984). Patrons, clients and friends: Interpersonal relations and the structure of trust in society. Cambridge: Cambridge University Press.

Fanon, F. (1963). The wretched of the earth. New York: Grove Press.

Foucault, M. (1980). The archaeology of knowledge. New York: Pantheon Books.

Freire, P. (1970). Pedagogy of the oppressed. (M. B. Ramos, Trans.). New York: Herder and Herder.

Freire, P. (1988). Pedagogy of the oppressed. New York: Continuum.

Gordon, A. (1997). Ghostly matters: Haunting and the sociological imagination. Minneapolis: University of Minnesota Press.

Greene, M. (2001). Variations on a blue guitar: The Lincoln Center Institute Lectures on Aesthetic Education. New York: Teachers College Press. 
Grinberg, J., \& Saavedra, E. (2000). The constitution of bilingual/ESL education as a disciplinary practice: Genealogical explorations. Review of Educational Research, 70(4), 419-441.

Grinberg, J., Goldfarb, K., \& Saavedra, E. (2005). Con coraje y con pasion: The schooling of Latinas/ os and their teachers' education. In P. Pedraza \& M. Rivera (Eds.), Latino education: An agenda for community action research. A volume of the National Latino/a Education Research and Policy Projects (pp. 227-254). Mahwah, NJ: Lawrence Erlbaum Associates.

Kozoll, R., \& Osborne, M. (2004). Finding meaning in science: Life world, identity and self. Science Education, 88, 157-181.

Lipsitz, G. (1998). The possessive investment in whiteness. Philadelphia: Temple University Press.

Memmi, A. (1965). The colonizer and the colonized. Boston, MA: Beacon.

Noddings, N. (1984). Caring: A feminine approach to ethics and moral education. Berkeley: University of California Press.

Roniger, L. (1990). Hierarchy and trust in modern Mexico and Brazil. New York: Praeger.

Spivak, G. C. (1988). Can the subaltern speak? In C. Nelson \& L. Grossberg (Eds.), Marxism and the interpretation of culture (pp. 271-313). Basingstoke: Macmillan Education.

Angela Calabrese Barton, is an associate professor of science education at Michigan State University. Drawing from critical and feminist theories, her research focuses on high poverty urban middle school youths' scientific literacies in and out of school and on the preparation of teachers to teach science in high poverty urban communities. Her research appears in the Journal of Research in Science Teaching, the International Journal of Science Education, the Journal of Curriculum Studies, the High School Journal, and Curriculum Inquiry among other journals.

Jaime Grinberg is a professor of educational foundations at Montclair State University in New Jersey, USA. He obtained his doctorate from Michigan State University and has taught and lectured at numerous institutions in the USA, Mexico, Argentina, and Israel among other places. Recently he published a book about the history of progressive teacher education, Teaching Like That: The Beginnings of Teacher Education at Bank Street and co-edited Common Questions, Disparate Voices: A Philosophical Conversation On Education. His forthcoming book, The Critical Curriculum: Eleven Questions, is geared for a broad audience of practitioners, policy makers, parents, and other care givers. He has also published his research and theoretical analysis in research handbooks, in journals such as Teachers College Record, Review of Educational Research, Educational Administration Quarterly, and Theory Into Practice among others, and as book chapters. He teaches undergraduate classes on global issues and on the history and philosophy of eEducation, as well as teaches masters and doctoral classes on issues of language, culture and power, and on the history and politics of curriculum and teaching.

Katherine Richardson Bruna is an assistant professor of multicultural and international curriculum studies at Iowa State University. She is a former bilingual instructional aide and ESL teacher. Before taking her current academic position, she worked as a research scientist at the American Institutes for Research and was involved in evaluations of the implementation and effects of Proposition 227, California's "English-Only" initiative, and of California's Professional Development Institutes for teachers of English Learners. She has a long-standing interest in issues related to the education of Mexican immigrant children in U.S. schools. Her most recent research on the science-learning experiences of these youth has taken her into schools, communities, and households of rural central Mexico. She teaches undergraduate and graduate courses in multiculturalism and multicultural education, and on bilingualism, bilingual education, and U.S. Mexican youth. 